\title{
Effect of Sea-Buckthorn (Hippophaë rhamnoides L.) Pulp Oil Consumption on Fatty Acids and Vitamin A and E Accumulation in Adipose Tissue and Liver of Rats
}

\author{
Sylwester Czaplicki ${ }^{1}$ (D) Dorota Ogrodowska ${ }^{1} \cdot$ Ryszard Zadernowski $^{2}$. \\ Iwona Konopka ${ }^{1}$
}

Published online: 2 May 2017

(C) The Author(s) 2017. This article is an open access publication

\begin{abstract}
An in vivo experiment was conducted to determine the effect of sea-buckthorn pulp oil feeding on the fatty acid composition of liver and adipose tissue of Wistar rats and the liver accumulation of retinol, its esters and $\alpha$-tocopherol. For a period of 28 days, rats were given a modified casein diet (AIN-93) in which sea-buckthorn pulp oil, soybean oil and pork lard were used as sources of fat. Compared to the other fat sources, sea-buckthorn pulp oil was the most abundant in C16 fatty acids, carotenoids (mainly $\beta$-carotene) and tocopherols (mainly $\alpha$-tocopherol). Its consumption was reflected in an increased share of palmitoleic acid in adipose tissue and the liver and an increased level of retinol in liver tissues (this was not observed for its esters). Although the type of fat did not have a significant effect on the average content of $\alpha$ tocopherol in the liver, the variation of saturation of this tissue with $\alpha$-tocopherol was the lowest when rats were fed a diet containing sea-buckthorn oil. This experiment indicates the possibility of affecting adipose tissue and liver by a diet.
\end{abstract}

Keywords Sea-buckthorn oil $\cdot$ Fatty acids $\cdot \alpha$-tocopherol · $\beta$-carotene $\cdot$ Retinol $\cdot$ Animal study

Sylwester Czaplicki

selek@go2.pl

1 Chair of Plant Food Chemistry and Processing, Faculty of Food Sciences, University of Warmia and Mazury, Plac Cieszyński 1, 10-726 Olsztyn, Poland

2 Department of Agriculture and Economics, The Academy of Agrobusiness in Łomża, Studencka 19 Str, 18-402 Łomża, Poland

\section{Introduction}

Plant fats differ in the composition of fatty acids and accompanied lipid-soluble compounds [1]. Canola, soybean, sunflower and olive oils are a basic dietary source of polyunsaturated fatty acids (PUFA), especially those of the C18-chain length, which are precursors of essential long-chain fatty acids (e.g., arachidonic (ARA), docosahexaenoic (DHA), eicosapentaenoic (EPA), etc.) [2]. Other basic market fats, such as coconut and palm kernel oils, are a source of medium chain saturated acids broadly utilized in confectionery products, frying fats, chocolate, etc. In contrast, oils abundant in rare fatty acids, such as $\omega-3, \omega-7$, selected $\omega-9$ and conjugated are often components of nutraceutical supplements or functional food.

Fatty acids are primarily energy sources and membrane constituents for the human body, but they have also many other biological activities related to chain length, saturation and number and the position of double bonds [3]. For example, 18 chain length $\omega-3$ and $\omega-6$ acids may be converted into signalling molecules such as prostaglandins, leukotrienes and thromboxanes [4]. Similarly, rare in the typical diet palmitoleic acid ( $\omega-7)$ probably plays an important role in the regulation of hepatic versus adipocyte lipogenesis $[3,5]$. Consuming food rich in this acid may beneficially affect both energy, homeostasis and metabolic health [5], for example, trans-palmitoleic acid in plasma phospholipids is strongly inversely associated with incident T2 diabetes mellitus [6]. This acid also reduces appetite and may help to combat other diseases, although the mechanism of its action has not been fully elucidated [7, 8].

Although various food groups (e.g., fish) can deliver a proper quantity and quality of fatty acids, the unique trait and advantage of plant oils is the simultaneous supply of numerous regulatory and protective compounds such as sterols, 
tocols, carotenoids, and lipophilic phenolics [9, 10]. Nonrefined oils (such as cold-pressed oils from pumpkin, linseed, evening primrose and sea-buckthorn) are great examples of matrices rich in lipid-soluble bioactive substances [1]. Oil made from the pulp of sea-buckthorn is special in this regard because of its high level of carotenoids and tocols [11, 12]. Some sea-buckthorn genotypes could deposit up to ca. $530 \mathrm{mg}$ of carotenoids and up to ca. $200 \mathrm{mg}$ of tocols in $100 \mathrm{~g}$ of pulp oil, accompanied by a ca. $40 \%$ share of palmitoleic acid (C16:1, $\omega-7)$ [13]. Since the data [1] shows that sea-buckthorn pulp oil, compared to other biooils, is one of the richest sources of these compounds in nature, it is not surprising that the market offer of functional food products and supplements with this oil is still growing. Although its pulp oil concentration is relatively low (approx. 3-5\% of wet moisture), this morphological part may constitute up to $90 \%$ of total fruit and, in this regard, can be regarded as an efficient source of valuable oil.

Even if a human meal contains a nutritionally-appropriate composition of compounds, the physiological utilization of individual components depends on its solubilisation from the food matrix, uptake from the small intestine and subsequent transformation into chylomicrons and lipoproteins $[14,15]$. Plasma delivery of lipid-origin compounds (such as $\alpha$ tocopherol) is also affected by body/tissue saturation with this compound [16]. Generally, the absorbed fatty acids and low molecular lipophilic compounds are utilized at once or deposited as storage material, mainly in adipose tissue and the liver.

The main aim of this study was to determine if the consumption of sea-buckthorn pulp oil (compared to soybean oil and pork lard as a control diet lipids, which are highly differentiated in fatty acids and phytochemicals composition) affects the fatty acid profile of liver and adipose tissue of Wistar rats fed a modified casein diet (AIN-93). The second aim was to test if an increased concentration of carotenoids and tocopherols in sea-buckthorn pulp oil may affect retinol and its esters and the $\alpha$-tocopherol content in the liver of the tested animals.

\section{Materials and Methods}

\section{Study Material}

Pork lard and soybean (Glycine max L.) oil were bought as foodstuffs at a retail outlet. Sea-buckthorn pulp oil was obtained from a laboratory. For this purpose, the fruit was disintegrated (MPW-324 homogeniser, Mechanika Precyzyjna, Warsaw, Poland) and then pressed with a hydraulic press (DEMA VertriebsGmbH, Im Tobel, Germany. The obtained juice was centrifuged at ca. 13,000 x g (5810R Eppendorf AG centrifuge, Hamburg, Germany) to separate liberated oil. The oil was collected, washed and purified by repeated centrifuging. The used fats were analysed for the content of carotenoids, tocopherols and fatty acid composition.

\section{In Vivo Nutritional Test}

The experiment was carried out at the Department of Biological Function of Food, Institute of Animal Reproduction and Food Research of Polish Academy of Sciences, Olsztyn, Poland. All procedures and experiments complied with the guidelines and were approved by the Local Ethics Commission of the University of Warmia and Mazury in Olsztyn, Poland. Male rats (aged eight weeks) of the Wistar strain were fed for 28 days on a modified casein diet for laboratory rodents (AIN-93) composed of: fructose $(30 \%)$, maize starch $(29.5 \%)$, casein $(20 \%)$, fat $(10 \%)$, cellulose $(5 \%)$, cholesterol $(0.5 \%)$, mineral mix $(3.5 \%)$, vitamin mix (1\%), DL-methionine $(0.3 \%)$ and cholic acid $(0.2 \%)$.

A total of 24 animals were divided into three distinct groups (each of eight rats) fed on pork lard, soybean oil and sea-buckthorn oil as a fat source. Animals were fed ad libitum with continuous access to distilled water and maintained under standard conditions (temperature of $21-22^{\circ} \mathrm{C}$; relative humidity of $50-70 \%$ with intensive room ventilation $(15 \times / \mathrm{h}) ; 12-\mathrm{h}$ lighting regimen). At the termination of the experiment, the rats were anesthetized with sodium pentobarbital according to the recommendations for the euthanasia of laboratory animals $(50 \mathrm{mg} / \mathrm{kg}$ body weight) and material for analyses was taken. Liver and adipose tissue were homogenised and frozen until the time of the analyses of the neutral lipid fatty acid profile (adipose tissue and liver) and the content of retinol and its esters and tocopherols (only liver). The remaining animal tissues and blood were used in other experiments.

\section{Analytical Procedures}

\section{Isolation of Adipose Tissue and Liver fat}

Extraction was conducted according to the method of Hosotani and Kitagawa [17]. A sample $(0.2 \mathrm{~g})$ of ground tissue was weighed within an accuracy of $0.001 \mathrm{~g}$ and homogenised with $0.2 \mathrm{ml}$ of distilled water. The samples were then precipitated with $0.8 \mathrm{~mL}$ of ethanol $(96 \%)$ and lipophilic compounds were extracted using $1 \mathrm{~mL}$ of hexane in triplicate. The solvent was evaporated at $30^{\circ} \mathrm{C}$ at a reduced pressure in an Eppendorf rotary concentrator (Eppendorf AG, Hamburg, Germany). Extracts were dissolved in hexane, centrifuged (5 min, ca. 13,000 x g) and taken for an assay of retinol, retinol esters, tocopherols and determination of the fatty acid profile. 


\section{Analytical Methods}

Fatty acid methyl esters were analysed by gas chromatography with a GC-MS QP2010 PLUS (Shimadzu, Japan) system according to the method described by Czaplicki et al. [11]. Briefly, fatty acid methyl esters were separated on a BPX70 $(25 \mathrm{~m} \times 0.22 \mathrm{~mm} \times 0.25 \mu \mathrm{m})$ capillary column (SGE Analytical Science, Victoria, Australia) with helium as the carrier gas at a flow rate of $0.9 \mathrm{~mL} /$ min. The column temperature was programmed as follows: a subsequent increase from 150 to $180{ }^{\circ} \mathrm{C}$ at the rate of $10^{\circ} \mathrm{C} / \mathrm{min}$, to $185{ }^{\circ} \mathrm{C}$ at the rate of $1.5{ }^{\circ} \mathrm{C}$ / min, to $250{ }^{\circ} \mathrm{C}$ at the rate of $30{ }^{\circ} \mathrm{C} / \mathrm{min}$ and a $10 \mathrm{~min}$ hold. The interface temperature of GC-MS was set at $240{ }^{\circ} \mathrm{C}$. The temperature of the ion source was $240{ }^{\circ} \mathrm{C}$ and the electron energy was $70 \mathrm{eV}$. The total ion current (TIC) mode was in the $50-500 \mathrm{~m} / \mathrm{z}$ range.

Carotenoids were analysed with a RP-HPLC technique according to Czaplicki et al. [11]. Briefly, the analysis was carried out using a 1200 series liquid chromatograph manufactured by Agilent Technologies (Palo Alto, CA, USA), equipped with a diode array detector (DAD) from the same manufacturer. Separation was performed at $30{ }^{\circ} \mathrm{C}$ on a YMC-C30 $250 \times 4.6 \mathrm{~mm}, 5 \mu \mathrm{m}$ column (YMC-Europe GmbH, Germany). A methanol- methyl tert-butyl ether (MTBE) gradient was programmed as it is presented in Table 1.

The absorbance was measured at the wavelength of $450 \mathrm{~nm}$ for carotenoids and $325 \mathrm{~nm}$ for retinol and retinol esters. Compounds were identified based on retention times of commercially available standards (Sigma-Aldrich Sp. z o.o., Poznań, Poland).

The analysis of tocopherols was carried out by the NPHPLC technique according to Czaplicki et al. [11]. Briefly, the analysis was performed using a 1200 series liquid chromatograph manufactured by Agilent Technologies (Palo Alto, CA, USA), equipped with a fluorescence detector from the same manufacturer. The separation was done on a Merck LiChrospher Si 60 column, $250 \mathrm{~mm} \times 4 \mathrm{~mm}, 5 \mu \mathrm{m}$. A $0.7 \%$ isopropanol solution in hexane at a $1 \mathrm{~mL} / \mathrm{min}$ flow rate was used as the mobile phase. The fluorescence detector was set at

Table 1 Parameters of the HPLC gradient used to separate carotenoids

\begin{tabular}{cllc}
\hline Time (min) & Flow rate (mL/min) & Methanol (\%) & MTBE (\%) \\
\hline 0 & 1 & 95 & 5 \\
5 & 1 & 95 & 5 \\
25 & 1.25 & 72 & 28 \\
33 & 1.25 & 5 & 95 \\
40 & 1 & 95 & 5 \\
60 & 1 & 95 & 5 \\
\hline
\end{tabular}

$296 \mathrm{~nm}$ for excitation and $330 \mathrm{~nm}$ for emission. Peaks were identified on the basis of retention times determined for $\alpha-, \beta-, \gamma-$ and $\delta$-tocopherol standards (Merck, Darmstadt, Germany) separately, and their content was calculated using external calibration curves.

The statistical analyses were carried out with the STATISTICA 10.0 PL package (StatSoft Polska sp. z o.o., Kraków, Poland). The average values were compared by means of a one-way analysis of variance with Duncan's test at $p=0.05$ as the critical level of significance.

\section{Results and Discussion}

\section{Fatty Acid Composition, Carotenoids and Tocopherols in Fats of Experimental Diets}

The fatty acid profile of experimental diets is shown in Table 2. Sea-buckthorn oil differed from other fats by its extremely high content of $\mathrm{C} 16$ fatty acids, in which the share of palmitic acid was $36.3 \%$ and palmitoleic acid was $41.0 \%$. Sea-

Table 2 Fatty acids composition (\%) and bioactive compounds content in fats used in experiment $(\mathrm{mg} / 100 \mathrm{~g})$

\begin{tabular}{|c|c|c|c|}
\hline Fatty acids & Pork lard & Soybean oil & Sea-buckthorn oil \\
\hline myristic $\mathrm{C}_{14: 0}$ & $1.89 \pm 0.05$ & trace & trace \\
\hline palmitic $\mathrm{C}_{16: 0}$ & $27.30 \pm 0.42$ & $12.90 \pm 0.62$ & $36.31 \pm 0.01$ \\
\hline palmitoleic $C_{16: 1 \omega 7}$ & $2.88 \pm 0.02$ & nd & $40.97 \pm 0.04$ \\
\hline stearic $\mathrm{C}_{18: 0}$ & $15.81 \pm 0.00$ & $3.12 \pm 0.02$ & $0.55 \pm 0.01$ \\
\hline oleic $C_{18: 1 \omega 9}$ & $45.94 \pm 0.28$ & $25.54 \pm 0.19$ & $8.77 \pm 0.11$ \\
\hline linoleic $\mathrm{C}_{18: 2 \omega 6}$ & $5.50 \pm 0.20$ & $52.49 \pm 0.71$ & $12.12 \pm 0.13$ \\
\hline$\alpha$-linolenic $\mathrm{C}_{18: 3 \omega 3}$ & $0.42 \pm 0.04$ & $5.95 \pm 0.09$ & $1.28 \pm 0.04$ \\
\hline$\gamma$-linolenic $\mathrm{C}_{18: 3 \omega 6}$ & $0.26 \pm 0.05$ & nd & nd \\
\hline SFA & 45.00 & 16.02 & 36,86 \\
\hline MUFA & 48.82 & 25.54 & 49.74 \\
\hline PUFA & 6.18 & 58.44 & 13.40 \\
\hline$\omega 3 / \omega 6$ ratio & 0.07 & 0.11 & 0.11 \\
\hline lutein & nd & trace & $3.24 \pm 0.49$ \\
\hline zeaxanthin & nd & nd & $1.65 \pm 0.14$ \\
\hline$\beta$-cryptoxanthin & nd & nd & 3.940 .36 \\
\hline$\alpha$-carotene & nd & nd & 6.900 .74 \\
\hline$\beta$-carotene & trace & trace & $118.36 \pm 9.58$ \\
\hline 9 -cis- $\beta$-carotene & trace & trace & $15.56 \pm 1.12$ \\
\hline unidentified & nd & nd & $56.39 \pm 5.01$ \\
\hline total carotenoids & trace & trace & $206.04 \pm 15.63$ \\
\hline$\alpha$-tocopherol & $3.06 \pm 0.41$ & $15.01 \pm 0.30$ & $144.14 \pm 4.10$ \\
\hline$\beta$-tocopherol & nd & nd & $3.98 \pm 0.23$ \\
\hline$\gamma$-tocopherol & nd & $53.35 \pm 5.32$ & $4.63 \pm 0.32$ \\
\hline$\delta$-tocopherol & nd & $31.03 \pm 1.61$ & $0.75 \pm 0.00$ \\
\hline total tocopherols & $3.06 \pm 0.41$ & $99.39 \pm 5.42$ & $153.50 \pm 4.25$ \\
\hline
\end{tabular}

nd - not detected 
buckthorn fruit oil may be considered as one of the richest source of palmitoleic acid $[18,19]$. The total share of PUFAs in this oil was only $13.4 \%$, with the prevalence of linoleic acid (ca. 90\%). Sea-buckthorn oil was similar in the share of saturated, mono and polyunsaturated acids to pork lard. The composition of soybean oil was quite different, with the prevalence of linoleic $(52.5 \%)$ and oleic $(25.5 \%)$ acids. The total share of PUFAs was $58.4 \%$, i.e., above 4 - and 9-fold higher than in seabuckthorn oil and in lard. The composition of used oils was consistent with previous data $[11,18,20,21]$.

Characteristic of carotenoids and tocols of experimental diets lipids is shown in Table 2. Sea-buckthorn oil contained considerable amounts of carotenoids $(206.0 \mathrm{mg} / 100 \mathrm{~g})$. This value lies within the limits given by other studies, although composition of this oil is generally highly variable in relation to cultivar, degree of fruit ripeness, origin of oil (from seed or fruit pulp) and method of extraction [22, 23]. Carotenoid-like compounds of this oil were classified as carotenes (ca. 68\% of total fraction), xanthophylls (ca. 4\%) and unidentified compounds (28\%). All-trans $\beta$-carotene prevailed (ca. $84 \%$ ) among carotenes. The presence of $\alpha$ - and 9-cis- $\beta$-carotene was also noted. Among xanthophylls, compounds such as lutein, zeaxanthin and $\beta$-cryptoxanthin were identified. Both comparative fat sources contained only traces of carotenoids.

In contrast, tocopherols were present in all tested fat matrices. The highest content of tocopherols $(153.5 \mathrm{mg} / 100 \mathrm{~g})$ was determined in sea buckthorn oil, and $\alpha$-tocopherol accounted for $94 \%$ of the total. Soybean oil was also abundant in tocopherols $(99.4 \mathrm{mg} / 100 \mathrm{~g}$ ), with the presence of $\gamma$ - (ca. 54\%), $\delta$ (ca. 31\%) and $\alpha$ - (ca. 15\%) homologues. The least rich and varied was pork lard, in which only the presence of $\alpha$ tocopherol in the amount of $3.1 \mathrm{mg} / 100 \mathrm{~g}$ was determined.

\section{Fatty Acid Composition of Adipose Tissue and Liver in Rats}

The fatty acid composition of animal tissue lipids is predominantly determined by dietary intake and endogenous synthesis [24]. The results of the present study indicate that the fatty acid profile of adipose tissue and liver was changed under the impact of different types of diet (Table 3). Independently of the used diet the adipose tissue was composed of four main fatty acids: palmitic, oleic, linoleic and palmitoleic, and the total share of these acids was close to $87 \%$ for rats feed with lard and sea-buckthorn oil and slightly higher (ca. 90\%) for soybean oil diet. Saturated acids such as myristic, pentadecanoic and stearic constituted from 6 to $9 \%$ of the total. Small amounts of vaccenic and $\alpha$-linolenic acids and traces of ARA and DHA acids were also found.

Although the total share of main fatty acids in adipose tissue appears to have been conserved, a high variation of individual acids was observed. It generally reflected the composition of fat in the diets, since, in all cases, the predominant fatty acids of the meal were also predominant in adipose tissue. It was found that feeding with lard resulted in the highest share of oleic and palmitic acids, with soybean oil in linoleic and oleic acids and with sea-buckthorn in palmitic, palmitoleic and oleic acids. This confirms that adipose tissue is the best indicator of the long-term dietary intake of fats [24]. The observed correlation between diet and composition of adipose tissue is important, since the texture of human storage fatty tissue (softness, rigidness, compactness) may be modified by the different composition of fats in a diet. It has been noted that a diet with sea-buckthorn oil caused a significant increase in the share of palmitoleic and vaccenic acids, accompanied by a simultaneous decrease of stearic and oleic acids. A similar high sensitivity of the fatty acid composition of adipose tissue to the type of diet was recently demonstrated by Chandrashekar et al. [25]. In experiments using coconut, soybean and sunflower oils they found that the share of administered fatty acids is reflected in the profile of fatty acids of this storage tissue, with the highest sensitivity of linoleic acid.

It was previously found that the fatty acid profile of liver differs from that of adipose tissue [25, 26]. Liver generally contains a lower share of oleic acid, but contains considerable amounts of long-chain PUFAs, such as ARA and DHA [25, 27]. The relative ratio of PUFA/SFA varies between $0.5-1.5$ in regard to the type of fat in the diet [25]. In our study, this ratio varied from 0.31 for lard to 1.34 for soybean oil (Table 3), but we suppose that it was slightly underestimated since we only analysed the neutral fat, which was hexane-extracted. The rat livers in our study had the highest share of oleic (23.8-42.4\% in relation to diet), palmitic (18.3-21.1\%) and linoleic (5.6$27.8 \%$ ) acids. These ranges are close to previous findings [25]. In contrast to the cited work, we found a high share of palmitoleic acid (8.9-19.3\% in relation to the diet), while the share of long-chain PUFAs was substantially lower. Especially noteworthy was the high share of palmitoleic acid $(19.3 \%)$ as a result of feeding with sea-buckthorn oil (a similar phenomenon as observed in adipose tissue). However, a similar effect was noted for lard containing only ca. $3 \%$ of palmitoleic acid. It shows that palmitoleic acid is preferentially deposited in the liver. There was a ca. $116 \%$ increase of this acid observed in the liver after the consumption of seabuckthorn pulp oil and ca. $46 \%$ increase after feeding with lard (in comparison to soybean oil - free of palmitoleic acid). This may have significant health consequences, since palmitoleic acid acts as a lipokine hormone and affects insulin sensitivity and fat accumulation in the liver [28].

\section{Retinol, Its Esters and $\alpha$-Tocopherol in Liver}

Dietary carotenoids and tocopherols, as other lipophilic components, are absorbed in the intestine via passive diffusion or via scavenger receptor class-B type I proteins after being incorporated into the micelles $[15,29,30]$. Inside the mucosal 
Table 3 Fatty acids composition in experimental animals' tissues (\%)

\begin{tabular}{|c|c|c|c|}
\hline & Pork lard & Soybean oil & Sea-buckthorn oil \\
\hline \multicolumn{4}{|l|}{ Adipose tissue } \\
\hline myristic $\mathrm{C}_{14: 0}$ & $2.58 \pm 0.97^{\mathrm{A}}$ & $1.93 \pm 0.16^{\mathrm{A}}$ & $2.25 \pm 0.40^{\mathrm{A}}$ \\
\hline pentadecanoic $\mathrm{C}_{15: 0}$ & $0.37 \pm 0.90^{\mathrm{A}}$ & $0.40 \pm 0.61^{\mathrm{A}}$ & $0.13 \pm 0.36^{\mathrm{A}}$ \\
\hline palmitic $\mathrm{C}_{16: 0}$ & $30.47 \pm 1.79^{\mathrm{A}}$ & $24.34 \pm 1.54^{\mathrm{B}}$ & $29.51 \pm 2.28^{\mathrm{A}}$ \\
\hline palmitoleic $\mathrm{C}_{16: 1 \omega 7}$ & $7.93 \pm 0.96^{\mathrm{A}}$ & $5.72 \pm 0.91^{\mathrm{B}}$ & $15.16 \pm 1.40^{\mathrm{C}}$ \\
\hline stearic $\mathrm{C}_{18: 0}$ & $6.21 \pm 0.59^{\mathrm{A}}$ & $4.15 \pm 0.34^{\mathrm{B}}$ & $3.91 \pm 0.67^{\mathrm{B}}$ \\
\hline oleic $\mathrm{C}_{18: 1 \omega 9}$ & $38.61 \pm 2.15^{\mathrm{A}}$ & $29.20 \pm 2.29^{\mathrm{B}}$ & $23.15 \pm 0.87^{\mathrm{C}}$ \\
\hline vaccenic $C_{18: 1 \omega 7}$ & $3.03 \pm 1.88^{\mathrm{A}}$ & $3.10 \pm 1.30^{\mathrm{A}}$ & $6.53 \pm 1.18^{\mathrm{B}}$ \\
\hline linoleic $\mathrm{C}_{18: 2 \omega 6}$ & $10.62 \pm 2.86^{\mathrm{A}}$ & $30.20 \pm 3.54^{\mathrm{B}}$ & $19.37 \pm 2.98^{\mathrm{C}}$ \\
\hline$\alpha$-linolenic $\mathrm{C}_{18: 3 \omega 3}$ & $0.19 \pm 0.37^{\mathrm{A}}$ & $0.95 \pm 0.76^{\mathrm{B}}$ & $0.00 \pm 0.00^{\mathrm{A}}$ \\
\hline arachidonic $\mathrm{C}_{20: 4} \omega 6$ & trace & trace & trace \\
\hline docosahexaenoic $\mathrm{C}_{22: 6 \omega 3}$ & trace & trace & trace \\
\hline SFA & 39.63 & 30.82 & 35.8 \\
\hline MUFA & 49.57 & 38.02 & 44.84 \\
\hline PUFA & 10.81 & 31.15 & 19.37 \\
\hline$\omega 3 / \omega 6$ ratio & 0.02 & 0.03 & - \\
\hline \multicolumn{4}{|l|}{ Liver tissue } \\
\hline miristic $\mathrm{C}_{14: 0}$ & $1.31 \pm 0.29^{\mathrm{A}}$ & $1.18 \pm 0.32^{\mathrm{A}}$ & $0.98 \pm 0.38^{\mathrm{A}}$ \\
\hline pentadecanoic $\mathrm{C}_{15: 0}$ & $0.35 \pm 0.10^{\mathrm{A}}$ & $0.52 \pm 0.34^{\mathrm{A}}$ & $0.44 \pm 0.17^{\mathrm{A}}$ \\
\hline palmitic $\mathrm{C}_{16: 0}$ & $21.11 \pm 3.32^{\mathrm{A}}$ & $18.35 \pm 3.15^{\mathrm{A}}$ & $19.89 \pm 1.99^{\mathrm{A}}$ \\
\hline palmitoleic $\mathrm{C}_{16: 1 \omega 7}$ & $13.07 \pm 2.21^{\mathrm{A}}$ & $8.94 \pm 2.66^{\mathrm{B}}$ & $19.30 \pm 1.96^{\mathrm{C}}$ \\
\hline stearic $\mathrm{C}_{18: 0}$ & $3.51 \pm 0.56^{\mathrm{A}}$ & $2.69 \pm 1.04^{\mathrm{B}}$ & $2.22 \pm 0.61^{\mathrm{B}}$ \\
\hline oleic $\mathrm{C}_{18: 1 \omega 9}$ & $42.45 \pm 2.74^{\mathrm{A}}$ & $28.75 \pm 1.62^{\mathrm{B}}$ & $23.85 \pm 0.99^{\mathrm{C}}$ \\
\hline vaccenic $\mathrm{C}_{18: 1 \omega 7}$ & $6.05 \pm 0.44^{\mathrm{A}}$ & $4.12 \pm 0.82^{\mathrm{B}}$ & $7.92 \pm 0.80^{\mathrm{C}}$ \\
\hline linoleic $\mathrm{C}_{18: 2 \omega 6}$ & $5.62 \pm 2.07^{\mathrm{A}}$ & $27.85 \pm 8.00^{\mathrm{B}}$ & $18.22 \pm 2.74^{\mathrm{C}}$ \\
\hline$\alpha$-linolenic $\mathrm{C}_{18: 3 \omega 3}$ & $0.19 \pm 0.09^{\mathrm{A}}$ & $0.91 \pm 0.42^{\mathrm{B}}$ & $0.64 \pm 0.16^{\mathrm{B}}$ \\
\hline arachidonic $\mathrm{C}_{20: 4} \omega 6$ & $0.29 \pm 0.11^{\mathrm{AB}}$ & $0.31 \pm 0.74^{\mathrm{A}}$ & $0.17 \pm 0.09^{\mathrm{B}}$ \\
\hline docosahexaenoic $\mathrm{C}_{22: 6} \omega 3$ & $1.99 \pm 1.13^{\mathrm{A}}$ & $1.55 \pm 0.90^{\mathrm{A}}$ & $1.73 \pm 0.79^{\mathrm{A}}$ \\
\hline other & $4.07 \pm 0.73^{\mathrm{A}}$ & $4.82 \pm 1.48^{\mathrm{A}}$ & $4.63 \pm 0.80^{\mathrm{A}}$ \\
\hline SFA & 26.28 & 22.74 & 23.53 \\
\hline MUFA & 61.57 & 41.81 & 51.07 \\
\hline PUFA & 8.09 & 30.62 & 20.76 \\
\hline$\omega 3 / \omega 6$ ratio & 0.37 & 0.09 & 0.13 \\
\hline
\end{tabular}

Values within a row with different letters (A,B,C $\ldots)$ are significantly different $(p=0.05)$ cells, they are incorporated into the chylomicrons and then released to the lymph. Chylomicrons are then catabolized to their remnants, incorporated into the lipoproteins at the site of the liver and then released into the blood stream [30]. Carotenoids and tocopherols are absorbed differentially by various tissues, with the predominant intake of carotenoids by liver and adipose tissue [29, 31], whereas tocopherols by liver, lung, brain and reproductive tissues [15]. Current data show that the conversion efficiency of food $\beta$-carotene into retinol (vitamin $\mathrm{A}$ ) in humans ranges from $3.6: 1$ to $28: 1$ by weight [more details in 32] . Bioconversion is highly dependent on carotenoid structure, particularly on the most active all-trans $\beta$-isomer form [32]. Generally, created vitamin A can be stored in animal tissues very effectively [33]. In the case of tocopherols, the main form retained in human plasma is RRR- $\alpha$-tocopherol [6, 10]. Generally, tocopherol bioavailability, metabolism into vitamin $\mathrm{E}$ and excretion in faeces, bile and urine are tightly regulated, which prevents toxic accumulation even at high-dose supplementation [6].

The present study found the highest level of retinol and its esters in livers of rats fed a diet containing seabuckthorn oil (Table 4). The content of the substances under study in this sample was: $553.4 \mathrm{nmol} / \mathrm{g}$ for retinol and $190.8 \mathrm{nmol} / \mathrm{g}$ for its esters. The content of these compounds in a diet with soybean oil was lower by nearly $28 \%$ for retinol and $6 \%$ for its esters. The smallest content of retinol (293.8 nmol/g) and its esters (147.1 nmol/g) was found in the liver of rats fed a pork lard diet. 
Table 4 Retinol, retinol esters and $\alpha$-tocopherol in experimental animals' liver tissues

\begin{tabular}{|c|c|c|c|}
\hline & Retinol & Retinol esters & $\alpha$-tocopherol \\
\hline & \multicolumn{3}{|c|}{$\mathrm{nmol} / \mathrm{g}$} \\
\hline Pork lard & $293.85 \pm 93.76^{\mathrm{A}}$ & $147.08 \pm 49.95^{\mathrm{A}}$ & $77.60 \pm 28.87^{\mathrm{A}}$ \\
\hline Soybean oil & $397.25 \pm 78.09^{\mathrm{A}}$ & $179.93 \pm 23.19^{\mathrm{A}}$ & $104.05 \pm 50.78^{\mathrm{A}}$ \\
\hline Sea-buckthorn oil & $553.43 \pm 167.04^{\mathrm{B}}$ & $190.78 \pm 63.72^{\mathrm{A}}$ & $104.46 \pm 18.99^{\mathrm{A}}$ \\
\hline
\end{tabular}

Values within a column with different letters $(\mathrm{A}, \mathrm{B} \ldots)$ are significantly different $(p=0.05)$
In total, the presence of sea-buckthorn oil in diet, in relation to feeding with pork lard, resulted in ca. $40 \%$ increase in liver saturation with vitamin A-like compounds. Guliyev et al. [7] confirmed the beneficial effect of sea-buckthorn oil in the treatment and protection of the liver. The cited authors stated that this oil considerably inhibited the formation of malondialdehyde in livers exposed to $\mathrm{CCl}_{4}$, ethanol, and paracetamol. Sea-buckthorn oil also decreased the level of alanine transaminase induced by $\mathrm{CCl}_{4}$ and paracetamol and prevented exhaustion of glutation in livers damaged by acetaminophen.

Although sea-buckthorn oil was the richest source of tocopherols, with $\alpha$-tocopherol being the dominant homologue, the content of $\alpha$-tocopherol in the analysed livers was similar in all feeding options (Table 4). It varied from $77.6 \mathrm{nmol} / \mathrm{g}$ for pork lard to ca. $104 \mathrm{nmol} / \mathrm{g}$ for both oils. These values are significantly higher than the data obtained by Jurczuk et al. [8], who determined the concentration of vitamin $\mathrm{E}$ in rat livers as being close to $20 \mu \mathrm{g} / \mathrm{g}$ of tissue. The important observation of our study was that the lowest coefficient of variation $(18.2 \%)$ of this compound was found in the group of rats fed sea-buckthorn oil (for comparison, its value for soybean oil was $48.8 \%$ and for lard $37.2 \%$ ). This may show that with a sea-buckthorn oil diet there was a saturation of liver with this compound. Asadian et al. [34] studied the degree of $\alpha$ tocopherol absorption in the liver of sheep fed with its addition and found no significant increase in the liver under supplementation.

\section{Conclusions}

It was found that the fatty acid profile of sources of fat in a diet was reflected in the composition of the adipose tissue and liver of rats. The addition of sea-buckthorn oil to fodder significantly increased the share of palmitoleic and vaccenic acids and simultaneously decreased the share of stearic and oleic acids in both analysed tissues. This oil was also a rich source of carotenoids and tocopherols in the diet, especially $\beta$ carotene and $\alpha$-tocopherol, the homologues with the highest biological values. The delivered carotenoids were bioconverted into retinol and its esters and they increased the total concentration of these compounds in the liver. Despite the highest content of $\alpha$-tocopherol, sea-buckthorn oil did not have a significant effect on its medium level in rat livers because of high individual variability of biological response between used animals.

Acknowledgements The authors wish to express their gratitude to Professor Zenon Zduńczyk and his team for carrying out the nutritional experiment.

\section{Compliance with Ethical Standards}

Conflict of Interest The authors declare that they have no conflict of interest.

Open Access This article is distributed under the terms of the Creative Commons Attribution 4.0 International License (http:// creativecommons.org/licenses/by/4.0/), which permits unrestricted use, distribution, and reproduction in any medium, provided you give appropriate credit to the original author(s) and the source, provide a link to the Creative Commons license, and indicate if changes were made.

\section{References}

1. Czaplicki S, Ogrodowska D, Derewiaka D et al (2011) Bioactive compounds in unsaponifiable fraction of oils from unconventional sources. Eur J Lipid Sci Technol 113:1456-1464

2. Abedi E, Sahari MA (2014) Long-chain polyunsaturated fatty acid sources and evaluation of their nutritional and functional properties. Food Sci Nutr 2:443-463

3. Reena MB, Krishnakantha TP, Lokesh BR (2010) Lowering of platelet aggregation and serum eicosanoid levels in rats fed with a diet containing coconut oil blends with rice bran oil or sesame oil. Prostaglandins Leukot Essent Fat Acids 83:151-160

4. Kratz M, Baars T, Guyenet S (2013) The relationship between highfat dairy consumption and obesity, cardiovascular, and metabolic disease. Eur J Nutr 52:1-24

5. Punita A, Chaturvedi A (2000) Effect of feeding crude red palm oil (Elaeis guineensis) and grain amaranth (Amaranthus paniculatus) to hens on total lipids, cholesterol, PUFA levels and acceptability of eggs. Plant Foods Hum Nutr 55:147-157

6. Lemaire-Ewing S, Desrumaux C, Néel D, Lagrost L (2010) Vitamin $\mathrm{E}$ transport, membrane incorporation and cell metabolism: is $\alpha$-tocopherol in lipid rafts an oar in the lifeboat? Mol Nutr Food Res 54:631-640

7. Guliyev BV, Gul M, Yildirim A (2004) Hippophae rhamnoides L.: chromatographic methods to determine chemical composition, use in traditional medicine and pharmacological effects. Biomed Relev Plant Components Act Princ Toxicants 812:291-307

8. Jurczuk M, Moniuszko-Jakoniuk J, Brzóska MM, Roszczenko A (2005) Vitamins E and C concentrations in the liver and kidney of 
rats exposed to cadmium and ethanol. Polish J Environ Stud 14: 599-604

9. Van Rooyen J, Esterhuyse AJ, Engelbrecht AM, Du Toit EF (2008) Health benefits of a natural carotenoid rich oil: a proposed mechanism of protection against ischaemia/reperfusion injury. Asia Pac J Clin Nutr 17:316-319

10. Szabolcs P, Angelika F, Roos FF et al (2016) A systematic review of global alpha-tocopherol status as assessed by nutritional intake levels and blood serum concentrations. Int J Vitam Nutr Res 86:1-21

11. Czaplicki S, Tańska M, Konopka I (2016) Sea-buckthorn oil in vegetable oils stabilisation. Ital J Food Sci 28:412-425

12. Teleszko M, Wojdyło A, Rudzińska M et al (2015) Analysis of lipophilic and hydrophilic bioactive compounds content in sea buckthorn (Hippophaë rhamnoides L.) berries. J Agric Food Chem 63:4120-4129

13. Kumar R, Kumar GP, Chaurasia OP, Singh SB (2011) Phytochemical and pharmaceutical profile of seabuckthorn oil: a review. Res J Med Plants 5:491-499

14. Van Rooyen J, Esterhuyse AJ, Engelbrecht AM, Du Toit EF (2008) Health benefits of a natural carotenoid rich oil: a proposed mechanism of protection against ischaemia/reperfusion injury. Asia Pac J Clin Nutr 17:316-319

15. Gagné A, Wei SQ, Fraser WD, Julien P (2009) Absorption, transport, and bioavailability of vitamin e and its role in pregnant women. J Obstet Gynaecol Can 31:210-217

16. Stocker A (2004) Molecular mechanisms of vitamin E transport. Ann N Y Acad Sci 1031:44-59

17. Hosotani K, Kitagawa M (2003) Improved simultaneous determination method of $\beta$-carotene and retinol with saponification in human serum and rat liver. J Chromatogr B 791:305-313

18. Yang B, Kallio H (2002) Composition and physiological effects of sea buckthorn (Hippophae) lipids. Trends Food Sci Technol 13: 160-167

19. Cenkowski S, Yakimishen R, Przybylski R, Muir WE (2006) Quality of extracted sea buckthorn seed and pulp oil. Can Biosyst Eng 48:9-16

20. Wood JD, Enser M, Fisher AV et al (2008) Fat deposition, fatty acid composition and meat quality: a review. Meat Sci 78:343-358

21. Martin CA, Visentainer JV, De Oliveira AN et al (2008) Fatty acid contents of Brazilian soybean oils with emphasis on trans fatty acids. J Braz Chem Soc 19:117-122
22. Czaplicki S, Nowak-Polakowska H, Zadernowski R (2005) Biological activity of lipophilic fraction of sea-buckthorn fruits in relation to the contents of carotenoids and tocopherols. Bromatol Chem Toksykol 38:185-188

23. Andersson SC, Olsson ME, Johansson E, Rumpunen K (2009) Carotenoids in sea buckthorn (Hippophae rhamnoides L.) berries during ripening and use of pheophytin a as a maturity marker. J Agric Food Chem 57:250-258

24. Hodson L, Skeaff CM, Fielding BA (2008) Fatty acid composition of adipose tissue and blood in humans and its use as a biomarker of dietary intake. Prog Lipid Res 47:348-380

25. Chandrashekar P, Lokesh BR, Gopala Krishna AG (2010) Hypolipidemic effect of blends of coconut oil with soybean oil or sunflower oil in experimental rats. Food Chem 123:728-733

26. Delaš I, Popović M, Petrović T et al (2008) Changes in the fatty acid composition of brain and liver phospholipids from rats fed fat-free diet. Food Technol Biotechnol 46:278-285

27. Arterburn LM, Hall EB, Oken H (2006) Distribution, interconversion, and dose response of n-3 fatty acids in humans. Am J Clin Nutr 83:1467S-1476S

28. Cao H, Gerhold K, Mayers JR, Wiest MM, Watkins SM, Hotamisligil GS (2008) Identification of a lipokine, a lipid hormone linking adipose tissue to systemic metabolism. Cell 2008134:933-944

29. Rao AV, Rao LG (2007) Carotenoids and human health. Pharmacol Res 55:207-216

30. Canene-Adams K, Erdman JW (2009) Absorption, transport, distribution in tissues and bioavailability. In: Britton G, Pfander H, Liaaen-Jensen S (eds) Carotenoids. Birkhäuser Basel, Basel, pp $115-148$

31. Kiokias S, Proestos C, Varzakas T (2016) A review of the structure, biosynthesis, absorption of carotenoids-analysis and properties of their common natural extracts. Curr Res Nutr Food Sci 4:25-37

32. Grune T, Lietz G, Palou A et al (2010) $\beta$-carotene is an important vitamin A source for humans. J Nutr 140:2268-2285

33. Tang G (2010) Bioconversion of dietary provitamin A carotenoids to vitamin a in humans. Am J Clin Nutr 91:1468-1473

34. Asadian A, Mezes M, Mirhadi SA (1996) Effect of vitamins A and $\mathrm{E}$ on blood plasma vitamin status and daily body mass gain of different fat-tailed sheep breeds. Acta Vet Hung 44:99-109 